\title{
Serum Lipid Profile Changes After Bariatric Surgery
}

\author{
Alireza Khalaj ${ }^{1,2}$, Arash Salman Yazdi ${ }^{3,{ }^{*}}$, Zary Sabet ${ }^{4}$, Maryam Abbasi ${ }^{3}$, Saiedeh Jafari ${ }^{3}$, Zohre Kaedi $^{3}$ \\ and Soheil Omidmalayeri ${ }^{3}$

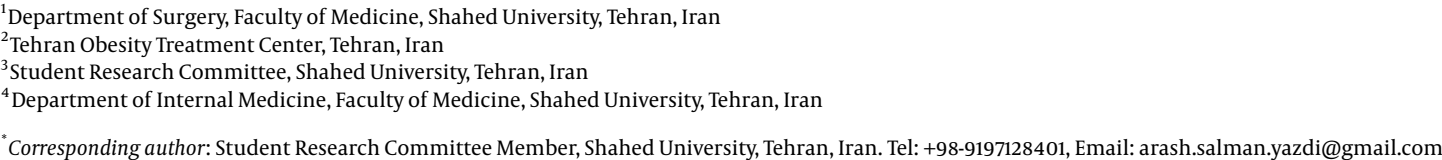

Corresponding author: Student Research Committee Member, Shahed University, Tehran, Iran. Tel: +98-9197128401, Email: arash.salman.yazdi@gmail.com

Received 2014 January 07; Revised 2018 December 23; Accepted 2018 December 25.

\begin{abstract}
Background: Obesity is accompanied by a number of comorbidities that gravely lower patients' quality of life; one such comorbidity is serum lipid abnormalities. Studies have shown that weight loss decreases serum total cholesterol and low-density lipoprotein (LDL) cholesterol and increases high-density lipoprotein (HDL) cholesterol. Bariatric surgery is one of the most recent ways to treat obesity and manage weight loss in overweight patients whose options for weight loss are limited.

Objectives: The aim of this study was to assess the effect of bariatric surgery on lipid profile of surgical candidates during the three months of post-operative care.

Methods: This prospective study was performed among 36 obese candidates of bariatric surgery at Mostafa Khomeini Hospital in Tehran, Iran from April to September of 2012. Body mass index (BMI), serum cholesterol, triglyceride, HDL and LDL levels were measured before and three months following the surgical intervention.

Results: The mean age of the participants was $35.39 \pm 10.32$ years. Mean body mass index (BMI) of the patients before surgery was $46.74 \pm 6.71 \mathrm{~kg} / \mathrm{m}^{2}$, which was lowered to $38.24 \pm 5.31 \mathrm{~kg} / \mathrm{m}^{2}$ after the intervention. Assessments showed a statistically significant increase in the serum level of HDL and a statistically significant decrease in the serum level of triglycerides, but no significant change in the serum level of cholesterol or LDL was noted. Moreover, results showed a positive correlation between serum LDL variations and changes in BMI.

Conclusions: Our findings showed that bariatric surgery improves weight loss and can help with managing or treating co-morbid illnesses through reducing triglyceride level and increasing HDL level, both of which improve patients' long-term cardiac, hepatic and endocrine health status.
\end{abstract}

Keywords: Sleeve Gastrectomy, Gastric Bypass, Bariatric Surgery, Lipid Profile, Triglyceride, Cholesterol

\section{Background}

The terms "Overweight" and "Obesity" refer to abnormal, excessive fat accumulation in an individual's body, which lead to overall health impairment $(1,2)$. Body mass index (BMI) is a parameter commonly calculated in order to identify an individual's weight status (3-5). According to the World Health Organization (WHO), a BMI greater than or equal to $25 \mathrm{~kg} / \mathrm{m}^{2}$ indicates a status of overweight and a BMI greater than or equal to $30 \mathrm{~kg} / \mathrm{m}^{2}$ indicates obesity (3). Genetics, heredity, environmental and psychological factors, lack of adequate physical activity and hormonal imbalances all play a part in the pathophysiology of overweight and obesity, but the most influential factor is the inequality between total caloric intake and expenditure ( 1 , 5).

The prevalence of obesity is increasing; WHO reported that in 2014, 1.9 billion people over the age of 18 were suffering from overweight, 600 million of whom were obese and morbidly obese individuals. Also, 41 million children under the age of 5 are suffering from obesity (3). It is worth mentioning that obesity is the third preventable cause of death, following tobacco usage (6).

Obesity is associated with raised cardiovascular risk factors such as hypertension, type 2 diabetes mellitus and dyslipidemia (6). Abnormalities of lipid profile associated with obesity include increased serum level of total cholesterol, low-density lipoprotein (LDL) cholesterol, very low density lipoprotein (VLDL) cholesterol, triglycerides, apolipoprotein $\mathrm{B}$ and a reduction in serum high-density lipoprotein (HDL) cholesterol (7).

Studies showed that a weight loss equal to $1 \mathrm{~kg}$ results in a drop in serum total cholesterol by $0.05 \mathrm{mmol} / \mathrm{L}$ and 
LDL cholesterol by $0.02 \mathrm{mmol} / \mathrm{L}$ and an increase in HDL cholesterol by $0.009 \mathrm{mmol} / \mathrm{L}(8)$. The most widely accepted treatment plans for treating obesity and overweight include a single approach or a combination of the following: Diet therapy, physical activity (aerobic primarily), behavioral therapy (e.g., treating underlying psychological enablers of eating disorders), pharmacotherapy and at last resort, surgical intervention (9). Indications for bariatric surgery include morbid obesity (a BMI higher than 40 $\left.\mathrm{kg} / \mathrm{m}^{2}\right)$ and severe obesity $\left(\mathrm{BMI}=35-40 \mathrm{~kg} / \mathrm{m}^{2}\right)$ in a patient with co-morbid conditions such as diabetes or hypertension (10).

Regarding morbidly obese patients as the target group, bariatric surgery is a highly successful method in reaching long-term health improvements and decreased mortality rates (11). Furthermore, bariatric surgery can lead to improved glucose metabolism and lowered cardiovascular risk (12-16). Overall, bariatric surgery can improve serum lipid concentrations (17-19). However, when we become specific regarding which components of the lipid panel are affected, one study reported improvement in all components of the lipid profile of patients before and after surgery, another reported a reduction only in triglyceride and LDL levels, but no statistically significant changes were observed in HDL and total cholesterol components of the lipid profile (20-23).

\section{Objectives}

So far, several studies have been conducted in order to assess the effects of bariatric surgery on lipid profile, which have yielded diverse results, especially on the improvement of lipid profile components. Thus, the aim of the present study was to assess the effects of two different bariatric surgical interventions, namely laparoscopic sleeve gastrectomy and Roux-en-Y gastric bypass, on lipid profile before and three months after the operation.

\section{Methods}

This prospective study was performed at Mostafa Khomeini General Hospital affiliated to Shahed Medical University in Tehran, Iran from April to September of 2012.

\subsection{Sample Size and Population}

The study was carried out among patients referred to the surgical clinic of Mostafa Khomeini General Hospital seeking treatment for their overweight or obesity (either with or without comorbidities) from April to September 2012. Thirty-six patients previously diagnosed with either morbid or severe obesity were chosen based on simple random sampling technique out of all surgical candidates.

\subsection{Participants and Inclusion Criteria}

The inclusion criteria comprised having undergone pre-surgical workup, being aged 20 - 62 years, not being pregnant (for female participants), not having been previously diagnosed with hypercholesterolemia and/or hypertriglyceridemia, and not being under treatment for high cholesterol or triglyceride levels prior to being chosen as a surgical candidates. Each patient underwent evaluations including routine blood tests, upper-endoscopy (evaluating the presence of gastroesophageal reflux disease, hiatal hernia, gastritis, and H. pylori infection status), ultrasonographic assessment of the whole abdomen with particular focus on the liver and the gallbladder (mainly for the presence or absence of cholelithiasis).

\subsection{Intervention}

All the patients underwent either sleeve gastrectomy (SG) or Roux-en-Y gastric bypass surgery. The method of surgery was chosen by the team of bariatric surgeons (independent from our study) for each patient based on thorough pre-surgical consultation, interviews and clinical assessments.

\subsection{Exclusion Criteria}

The exclusion criteria included age below 20 or above 62 years, unwillingness to participate, previous history of another form of bariatric surgery, lack of compliance with follow up visits three months after undergoing the surgery, refusal to adhere to post-surgical instructions, endocrine comorbidities other than hypertriglyceridemia and/or hypercholesterolemia (e.g., hyper and hypothyroidism, Cushing's syndrome and hyperprolactinemia) and underlying hepatic diseases marked by elevated liver transaminase in blood test or hepatomegaly defined in abdominal ultrasonography report.

\subsection{Ethics Committee}

Institutional approval of ethics committee was obtained and all the patients received detailed information regarding the research and counseling prior to the surgery. Signed consent forms were also obtained from all the participants before their enrolment in the study.

\subsection{Data Collection}

The interview was performed and the questionnaire was compiled by a medical student after having received appropriate training. Demographic information such as age and sex were recorded. Anthropometric specifications including weight (within 100-gram accuracy) and height (within 0.5-centimeter accuracy) were evaluated by minimal clothing, without shoes, using a digital scale and a 
standard meter, followed by the calculation of BMI as the gold standard for the diagnosis of obesity.

Serum levels of total cholesterol, triglyceride, LDL and HDL were measured directly by enzymatic methods and all the tests were performed in one laboratory (Shafagh Pathobiology Laboratory, ELISA).

Three months after surgery, interviews were conducted again and each patient's BMI three months after the surgery was calculated. Total cholesterol, triglyceride, HDL and LDL levels of serum were assessed again.

\subsection{Statistical Analysis}

Data was analyzed using SPSS software (V. 22, SPSS Inc., Chicago, USA). To express the quantitative measurements, mean and standard deviation (SD) were used. For nominal variables, relative frequencies were reported. Also, univariate statistical analysis and Spearman test were applied. Two-tailed P value of less than 0.05 was considered significant.

\section{Results}

In this study, 36 patients were enrolled, all of whom completed the study. The mean age of the patients was $35.39 \pm 10.32$ years (age range: 20 - 62 years old); $91.7 \%$ of the subjects were female and $8.3 \%$ were male. The mean BMI prior to the surgery was $46.74 \pm 6.71 \mathrm{~kg} / \mathrm{m}^{2}$ (range: 38.54 $65.79 \mathrm{~kg} / \mathrm{m}^{2}$ ) and the mean BMI post-operatively was 38.24 $\pm 5.31 \mathrm{~kg} / \mathrm{m}^{2}$ (range: $31.99-57.02 \mathrm{~kg} / \mathrm{m}^{2}$ ). Further characteristics of the participants are shown in Table 1.

Univariate comparisons showed significant differences in serum levels of HDL and triglyceride before and after surgery $(\mathrm{P}<0.023$ and $\mathrm{P}<0.001$, respectively), but no significant differences in the serum levels of cholesterol and $\mathrm{LDL}$ were noted $(\mathrm{P}<0.381$ and $\mathrm{P}<0.642$, respectively).

Investigations showed no correlation between BMI changes and changes in serum levels of total cholesterol, triglyceride and HDL $(\mathrm{P}=0.149, \mathrm{P}=0.103$ and $\mathrm{P}=0.107$, respectively), but change in serum LDL was positively correlated with change in BMI $(\mathrm{P}=0.037, \mathrm{r}=0.35)$. Table 2 summarizes the results of other univariate comparisons of the study variables.

\section{Discussion}

We evaluated the effect of two different bariatric surgical methods on lipid profile changes. Our findings showed significant differences in the serum levels of HDL and triglyceride before and after surgery, but no significant difference was found in the serum levels of total cholesterol and LDL before and after the surgery. Furthermore, investigations showed a positive correlation between changes in serum LDL and BMI.

Toolabi et al. showed significant improvement in all components of lipid profile one year after surgery (20). Golpaie et al. reported significant reduction in LDL and triglycerides levels six weeks post-surgery (21). Corradini et al. also reported significant changes and improvements in all the components of lipid profile in a three-year period (24). The results of all the mentioned studies were consistent with each other.

In another study, hyperlipidemia improved in $80 \%$ $100 \%(n=400)$ of the obese patients who underwent gastric bypass surgery (25). Another study reported that 72.3\% of patients previously diagnosed with hypertriglyceridemia had been normalized within 18 months after undergoing gastric banding (26).

The most important differences among the results of the aforementioned studies compared to each other and to the present study are pertained to the type of bariatric surgery, duration of the study and type of improved components of lipid profile. The discrepancy in results could also be attributed to follow up duration. In long-term follow-ups (2 years and more), assessments showed improvement in all components of lipid profile (24); thus, examining the effect of bariatric surgery on all components of lipid profile requires a longer course of follow-up visits post-operatively.

Possible mechanisms that may influence components of lipid profile in bariatric surgery are caloric restriction, weight loss (8), endocrine changes (27) and malabsorption (23). Each bariatric surgery leads to some extent of weight loss (28), and it seems that patients undergoing gastric bypass surgery experience more weight reduction (17). The correlation between weight loss and lipid level changes is a matter of debate, with some studies showing a positive correlation $(29,30)$ and some demonstrating no correlation (31-33). Our study demonstrated a positive correlation between change in serum LDL and change in BMI. Another possible mechanism is endocrine changes. It has been documented (34) that there is an increase in serum level of adiponectin in patients having undergone gastric bypass surgery. In this study, however, adiponectin level was not evaluated.

This study had some limitations that should be recounted here. First, the two types of surgery (sleeve gastrectomy and gastric bypass) were not randomly assigned. Second, low percentage of male patients may have influenced our results. Third, some confounding factors affecting serum lipid profile such as physical activity, dietary habits, alcohol consumption, or smoking status were not considered in this study due to difficulties regarding ob- 


\begin{tabular}{|c|c|c|c|}
\hline & Mean \pm SD & Min & Max \\
\hline \multicolumn{4}{|l|}{ Age } \\
\hline Pre/Post-op & $35.39 \pm 10.32$ & 20.00 & 62.00 \\
\hline \multicolumn{4}{|l|}{ Weight, kg } \\
\hline Pre-op & $121.19 \pm 10.36$ & 94.00 & 173.00 \\
\hline Post-op & $99.19 \pm 15.48$ & 77.00 & 132.00 \\
\hline \multicolumn{4}{|c|}{ Weight difference, kg } \\
\hline Post-op & $-22.00 \pm 9.91$ & -53.00 & -6.00 \\
\hline \multicolumn{4}{|l|}{ BMI, $\mathrm{kg} / \mathrm{m}^{2}$} \\
\hline Pre-op & $46.74 \pm 6.71$ & 38.54 & 65.79 \\
\hline Post-op & $38.24 \pm 5.31$ & 31.99 & 57.02 \\
\hline \multicolumn{4}{|c|}{ BMI changes, $\mathbf{k g} / \mathrm{m}^{2}$} \\
\hline Post-op & $-8.50 \pm 3.71$ & -21.23 & -2.31 \\
\hline \multicolumn{4}{|c|}{ Serum total cholesterol, mg/dL } \\
\hline Pre-op & $195.14 \pm 32.83$ & 128.00 & 283.00 \\
\hline Post-op & $190.17 \pm 38.37$ & 119.00 & 311.00 \\
\hline \multicolumn{4}{|c|}{ Serum total cholesterol changes, $\mathrm{mg} / \mathrm{dL}$} \\
\hline Post-op & $-4.97 \pm 33.62$ & -75.00 & 92.00 \\
\hline \multicolumn{4}{|c|}{ Serum triglyceride, mg/dL } \\
\hline Pre-op & $157.53 \pm 66.34$ & 58.00 & 296.00 \\
\hline Post-op & $107.81 \pm 48.11$ & 45.00 & 267.00 \\
\hline \multicolumn{4}{|c|}{ Serum triglyceride changes, $\mathrm{mg} / \mathrm{dL}$} \\
\hline Post-op & $-49.72 \pm 53.53$ & -198.00 & 28.00 \\
\hline \multicolumn{4}{|l|}{ Serum LDL, mg/dL } \\
\hline Pre-op & $117.25 \pm 22.21$ & 81.00 & 181.00 \\
\hline Post-op & $114.86 \pm 31.59$ & 55.00 & 218.00 \\
\hline \multicolumn{4}{|c|}{ Serum LDL changes, $\mathrm{mg} / \mathrm{dL}$} \\
\hline Post-op & $-2.39 \pm 30.59$ & -67.00 & 90.00 \\
\hline \multicolumn{4}{|l|}{ Serum HDL, mg/dL } \\
\hline Pre-op & $47.69 \pm 12.03$ & 24.00 & 75.00 \\
\hline Post-op & $52.72 \pm 11.71$ & 31.00 & 83.00 \\
\hline \multicolumn{4}{|c|}{ Serum HDL changes, mg/dL } \\
\hline Post-op & $5.03 \pm 12.65$ & -23.00 & 26.00 \\
\hline
\end{tabular}

Abbreviations: BMI, body mass index; HDL, high-density lipoprotein; LDL, low-density lipoprotein.

taining credible data (e.g., patients' lack of cooperation regarding self-reports of physical activity or tobacco and alcohol consumption). Nevertheless, it should be noted that this surgery is especially noticeable when other treatment modalities with different mechanisms have already failed to yield proper weight management, especially in patients diagnosed with grade 2 obesity (BMI score of $+35 \mathrm{~kg} / \mathrm{m}^{2}$ ) whose weight problem withholds them from being prop- erly able to exercise in order to lose weight (20-22). Finally, three-month follow-up period was rather short.

In conclusion, our findings showed a significant improvement in the serum levels of HDL and triglyceride before and after the surgical intervention. Furthermore, investigations demonstrated a positive correlation between changes in serum LDL and changes in BMI. In addition to the weight loss achieved by bariatric surgery, the associ- 


\begin{tabular}{llc}
\hline \multicolumn{2}{l}{ Table 2. Univariate Comparison of Study Variables } & \\
\hline & Age & BMI Changes \\
\hline Changes of serum level of cholesterol & $\mathrm{r}=0.058$ & $\mathrm{r}=0.246$ \\
\hline Changes of serum level of triglyceride & $\mathrm{r}=0.202$ & $\mathrm{r}=0.276$ \\
\hline Changes of serum level of HDL & $\mathrm{r}=0.297$ & $\mathrm{r}=0.273$ \\
Change of serum LDL & $\mathrm{r}=-0.034$ & $\mathrm{r}=0.350^{\mathrm{a}}$ \\
\hline BMI changes, $\mathbf{~ k g} / \mathbf{m}^{\mathbf{2}}$ & $\mathrm{r}=0.108$ & - \\
\hline
\end{tabular}

Abbreviations: BMI, body mass index; HDL, high-density lipoprotein; LDL, lowdensity lipoprotein.

${ }^{a}$ Correlation is significant at the 0.05 level (2-tailed).

ated risk factors such as dyslipidaemia are also expected to improve. It appears that triglyceride and HDL normalize faster.

\section{Acknowledgments}

We would like to thank Dr. Peyman Arian and Dr. Ali Ghanem for their assistance in conducting this study.

\section{Footnotes}

Conflict of Interests: All the contributing authors declare that they have no conflicts of interest.

Ethical Considerations: Institutional approval of ethics committee was obtained and all the patients received detailed information regarding the research and counseling prior to the surgery.

Funding/Support: This research was supported by Shahed University, Tehran, Iran.

Patient Consent: Signed consent forms were also obtained from all the participants before their enrolment in the study.

\section{References}

1. Labib M. acp best practice No 168. The investigation and management of obesity. J Clin Pathol. 2003;56(1):17-25. doi: 10.1136/jcp.56.1.17. [PubMed: 12499427]. [PubMed Central: PMC1769843].

2. Zhang Y, Proenca R, Maffei M, Barone M, Leopold L, Friedman JM. Positional cloning of the mouse obese gene and its human homologue. Nature.1994;372(6505):425-32. doi: 10.1038/372425a0. [PubMed: 7984236].

3. World Health Organization. Media Centre. Obesity and overweight. World Health Organization; 2012. Available from: http://www.who. int/mediacentre/factsheets/fs $311 / \mathrm{en} /$.

4. Curtin F, Morabia A, Pichard C, Slosman DO. Body mass index compared to dual-energy X-ray absorptiometry: Evidence for a spectrum bias. J Clin Epidemiol. 1997;50(7):837-43. doi: 10.1016/S08954356(97)00063-2. [PubMed: 9253396].

5. Smalley KJ, Knerr AN, Kendrick ZV, Colliver JA, Owen OE. Reassessment of body mass indices. Am J Clin Nutr. 1990;52(3):405-8. doi: 10.1093/ajcn/52.3.405. [PubMed: 2393001].
6. Sullivan PW, Ghushchyan VH, Ben-Joseph R. The impact of obesity on diabetes, hyperlipidemia and hypertension in the United States. Qual Life Res. 2008;17(8):1063-71. doi: 10.1007/s11136-008-9385-7. [PubMed: 18777200].

7. Grundy SM, Barnett JP. Metabolic and health complications of obesity. Dis Mon. 1990;36(12):641-731. [PubMed: 2261844].

8. Dattilo AM, Kris-Etherton PM. Effects of weight reduction on blood lipids and lipoproteins: A meta-analysis. Am J Clin Nutr. 1992;56(2):320-8. doi: 10.1093/ajcn/56.2.320. [PubMed: 1386186].

9. Orzano AJ, Scott JG. Diagnosis and treatment of obesity in adults: An applied evidence-based review. J Am Board Fam Pract. 2004;17(5):35969. doi: 10.3122/jabfm.17.5.359. [PubMed: 15355950].

10. Mun EC, Blackburn GL, Matthews JB. Current status of medical and surgical therapy for obesity. Gastroenterology. 2001;120(3):669-81. doi: 10.1053/gast.2001.22430. [PubMed: 11179243].

11. Christou NV, Sampalis JS, Liberman M, Look D, Auger S, McLean AP, et al. Surgery decreases long-term mortality, morbidity, and health care use in morbidly obese patients. Ann Surg. 2004;240(3):416-23. discussion 423-4. doi: 10.1097/01.sla.0000137343.63376.19. [PubMed: 15319713]. [PubMed Central: PMC1356432].

12. Gill RS, Karmali S, Sharma AM. Treating type 2 diabetes mellitus with sleeve gastrectomy in obese patients. Obesity (Silver Spring). 2011;19(4):701-2. doi: 10.1038/oby.2010.261. [PubMed: 20966914].

13. Peterli R, Wolnerhanssen B, Peters T, Devaux N, Kern B, ChristoffelCourtin C, et al. Improvement in glucose metabolism after bariatric surgery: Comparison of laparoscopic Roux-en-Y gastric bypass and laparoscopic sleeve gastrectomy: A prospective randomized trial. Ann Surg. 2009;250(2):234-41. doi: 10.1097/SLA.0b013e3181ae32e3. [PubMed: 19638921].

14. Lakdawala MA, Bhasker A, Mulchandani D, Goel S, Jain S. Comparison between the results of laparoscopic sleeve gastrectomy and laparoscopic Roux-en-Y gastric bypass in the Indian population: A retrospective 1 year study. Obes Surg. 2010;20(1):1-6. doi: 10.1007/s11695009-9981-9. [PubMed: 19802646].

15. Vidal J, Ibarzabal A, Nicolau J, Vidov M, Delgado S, Martinez G, et al. Short-term effects of sleeve gastrectomy on type 2 diabetes mellitus in severely obese subjects. Obes Surg. 2007;17(8):1069-74. doi: 10.1007/s11695-007-9180-5. [PubMed: 17953241].

16. Athyros VG, Tziomalos K, Karagiannis A, Mikhailidis DP. Cardiovascular benefits of bariatric surgery in morbidly obese patients. Obes Rev. 2011;12(7):515-24. doi: 10.1111/j.1467-789X.2010.00831.x. [PubMed: 21348922].

17. Sjostrom L, Lindroos AK, Peltonen M, Torgerson J, Bouchard C, Carlsson $\mathrm{B}$, et al. Lifestyle, diabetes, and cardiovascular risk factors 10 years after bariatric surgery. $N$ Engl J Med. 2004;351(26):2683-93. doi: 10.1056/NEJMoa035622. [PubMed: 15616203].

18. Dhabuwala A, Cannan RJ, Stubbs RS. Improvement in co-morbidities following weight loss from gastric bypass surgery. Obes Surg. 2000;10(5):428-35. doi: 10.1381/096089200321594291. [PubMed: 11054247].

19. Nguyen NT, Varela E, Sabio A, Tran CL, Stamos M, Wilson SE. Resolution of hyperlipidemia after laparoscopic Roux-en-Y gastric bypass. $J$ Am Coll Surg. 2006;203(1):24-9. doi:10.1016/j.jamcollsurg.2006.03.019. [PubMed: 16798484].

20. Toolabi K, Arefanian S, Golzarand M, Arefanian H. Effects of laparoscopic Roux-en-Y gastric bypass (LRYGB) on weight loss and biomarker parameters in morbidly obese patients: A 12-month follow-up. Obes Surg. 2011;21(12):1834-42. doi: 10.1007/s11695-011-05258. [PubMed: 21964796].

21. Golpaie A, Hosseinzadeh-Attar M, Hoseini M, Karbaschian Z, Talebpour M. Changes in lipid profile and insulin resistance in morbidly obese patients following laparoscopic total gastric vertical plication. J Minim Invasive Surg Sci. 2012;1(1):24-9. doi: 10.17795/minsurgery-2596. 
22. Auyang ED, Murayama KM, Nagle AP. Five-year follow-up after laparoscopic Roux-en-Y gastric and partial ileal bypass for treatment of morbid obesity and uncontrolled hyperlipidemia. Obes Surg. 2009;19(1):121-4. doi: 10.1007/s11695-008-9682-9. [PubMed: 18818980].

23. Benaiges D, Flores-Le-Roux JA, Pedro-Botet J, Ramon JM, Parri A, Villatoro $\mathrm{M}$, et al. Impact of restrictive (sleeve gastrectomy) vs hybrid bariatric surgery (Roux-en-Y gastric bypass) on lipid profile. Obes Surg. 2012;22(8):1268-75. doi: 10.1007/s11695-012-0662-8. [PubMed: 22544352].

24. Corradini SG, Eramo A, Lubrano C, Spera G, Cornoldi A, Grossi A, et al. Comparison of changes in lipid profile after bilio-intestinal bypass and gastric banding in patients with morbid obesity. Obes Surg. 2005;15(3):367-77. doi: 10.1381/0960892053576839. [PubMed: 15826472].

25. Peluso L, Vanek VW. Efficacy of gastric bypass in the treatment of obesity-related comorbidities. Nutr Clin Pract. 2007;22(1):22-8. doi: 10.1177/011542650702200122. [PubMed: 17242451].

26. Busetto L, Sergi G, Enzi G, Segato G, De Marchi F, Foletto M, et al. Short-term effects of weight loss on the cardiovascular risk factors in morbidly obese patients. Obes Res. 2004;12(8):1256-63. doi: 10.1038/oby.2004.159. [PubMed: 15340108].

27. Antunes H, Santos C, Carvalho S. Serum leptin levels in overweight children and adolescents. Br J Nutr. 2009;101(8):1262-6. doi: 10.1017/S0007114508055682. [PubMed: 18755049].

28. Buchwald H, Avidor Y, Braunwald E, Jensen MD, Pories W, Fahrbach
$\mathrm{K}$, et al. Bariatric surgery: A systematic review and meta-analysis. JAMA. 2004;292(14):1724-37. doi: 10.1001/jama.292.14.1724. [PubMed: 15479938].

29. Brolin RE, Kenler HA, Wilson AC, Kuo PT, Cody RP. Serum lipids after gastric bypass surgery for morbid obesity. Int J Obes. 1990;14(11):939 50. [PubMed: 2276855].

30. Wolf AM, Beisiegel U, Kortner B, Kuhlmann HW. Does gastric restriction surgery reduce the risks of metabolic diseases? Obes Surg. 1998;8(1):9-13. doi: 10.1381/096089298765554980. [PubMed: 9562480].

31. Kelly TM, Jones SB. Changes in serum lipids after gastric bypass surgery. Lack of a relationship to weight loss. Int JObes.1986;10(6):44352. [PubMed: 3804561].

32. Gleysteen JJ, Barboriak JJ. Improvement in heart disease risk factors after gastric bypass. Arch Surg. 1983;118(6):681-4. doi: 10.1001/archsurg.1983.01390060003001. [PubMed: 6847361].

33. Gonen B, Halverson JD, Schonfeld G. Lipoprotein levels in morbidly obese patients with massive, surgically-induced weight loss. Metabolism. 1983;32(5):492-6. doi: 10.1016/0026-0495(83)90012-4. [PubMed: 6843360].

34. Illan-Gomez F, Gonzalvez-Ortega M, Orea-Soler I, Alcaraz-Tafalla MS, Aragon-Alonso A, Pascual-Diaz M, et al. Obesity and inflammation: Change in adiponectin, C-reactive protein, tumour necrosis factor-alpha and interleukin-6 after bariatric surgery. Obes Surg. 2012;22(6):950-5. doi: 10.1007/s11695-012-0643-y. [PubMed: 22527592]. 